\author{
Cadernos de \\ ESTUDOS LINGUIISTIICOS - (58.3), Campinas, pp. 383-399 - set./dez. 2016
}

\title{
AAUTO-ORGANIZAÇÃO COMO MECANISMO PARA A RESOLUÇÃO DA VARIAÇÃO LINGUÍSTICA
}

\author{
MARCO ANTÔNIO DE OLIVEIRA ${ }^{1}$
}

\begin{abstract}
RESUMO: Este texto examina as maneiras pelas quais a variação linguística tende a ser resolvida. Para tanto adoto, de início, a perspectiva da linguagem como um sistema adaptativo complexo. Nessa perspectiva a linguagem é considerada também como um sistema não linear e dissipativo, que interage com o ambiente em que ocorre. A auto-organização é entendida aqui, de acordo com Camazine et al. (2001), como a emergência de uma ordem mais alta que se estabelece a partir da interação entre elementos mais baixos do sistema e que tem como mecanismo central a retroalimentação. A alegação principal desse texto é a de que um sistema linguístico que tenha sido perturbado por algum tipo de retroalimentação positiva acabará recuperando, ao longo do tempo, sua estabilidade através de uma retroalimentação negativa, sob a ação de atratores periódicos e não periódicos. Alguns casos de variação linguística no português brasileiro são retomados aqui para dar suporte à minha alegação principal. Ao final, apresento a sugestão de que o efeito dos atratores não periódicos tem precedência sobre a atuação de atratores periódicos, o que apoia a ideia de que qualquer análise da variação linguística deve considerar os aspectos etológicos e ecológicos da questão.
\end{abstract}

Palavras-Chave: Variação linguística; Sistemas adaptativos complexos; Resolução da variação.

ABSTRACT: This paper examines the ways by which linguistic variation tends to be resolved. I assume from the beginning that language is a complex adaptive system. As such it is also a nonlinear, dissipative system which interacts with its environment. Self-organization is understood here, following Camazine et al. (2001), as the emergence of a pattern at the global level of a system solely from numerous interactions among the lower-level components of the system and its core mechanism is feedback loop. The main point of this paper is that a linguistic system which has been disturbed by some kind of positive feedback will recover stability in the course of time through negative feedback under the action of periodic as well as non periodic attractors. Some cases of linguistic variation in Brazilian Portuguese are considered here to support the main claim. As a closing remark I suggest that the effect of non periodic attractors has some sort of precedence over the effect of periodic attractors. If this is really the case then we have support for the idea that any analysis of linguistic variation will have to take into consideration its ethological and ecological aspects.

Keywords: Linguistic variation; Complex adaptive systems; Resolution of variation.

${ }^{1}$ Pontifícia Universidade Católica de Minas Gerais. 


\section{INTRODUÇÃO}

As línguas naturais estão em constante estado de inovação, o que se pode perceber na variação (e na mudança) linguística. Por outro lado, as línguas também exibem uma tendência a "resolver" a variação criada. Em Oliveira (2009) sugeri que, embora as línguas não tenham como impedir o surgimento da variação linguística, há sempre uma tendência a resolvê-la, de um modo ou de outro.

Neste texto pretendo retomar a questão da resolução da variação linguística, na perspectiva da linguagem enquanto um sistema adaptativo complexo (SAC), mostrando que o mecanismo utilizado nesta resolução se identifica com a autoorganização, entendida como a emergência de uma ordem global, ou mais alta, que se dá através de interações locais, i.e., como resultado de interações entre os falantes individuais.

Vou assumir, como hipótese de trabalho, que a auto-organização se dá por um feedback negativo que age após um desequilíbrio provocado por um feedback positivo (cf. OLIVEIRA2014). Resumindo, é no feedback loop que os SAC's exibem o jogo constante entre desequilíbrio e equilíbrio, entre a perturbação e a preservação de uma estrutura, ou padrão. É evidente que a hipótese aqui proposta precisa ser entendida de modo dinâmico e não como algo que conduza a um estado fixo, uma vez que, por sua própria natureza, os SAC's estão em movimento constante.

Serão comentados ao longo do texto alguns tipos de manifestação do mecanismo de auto-organização, assim como os tipos de atratores que favorecem cada uma dessas diferentes maneiras de se promover a auto-organização. Ao final pretendo sugerir que a auto-organização leva em conta, em primeiro lugar, a atuação de atratores não periódicos para, em seguida, se valer de atratores periódicos na emergência de um novo padrão global.

\section{SOBRE A NOÇÃO DE LINGUAGEM}

Em Oliveira (2015:53) assumi, com base em Hauser, Chomsky e Fitch (2010), que a linguagem é um órgão que faz parte de um organismo maior, que é o ser humano. Acho conveniente retomar essa posição aqui para, na sequência, abordar o tema central deste texto.

Antes de tudo, é preciso especificar esse órgão denominado linguagem. Embora a linguagem seja tomada como um órgão, não se trata, é claro, de um órgão físico, mas de um órgão de natureza cognitiva (mental). Sua natureza enquanto órgão tem a ver com sua função específica, do mesmo modo que outros órgãos (físicos) valem por suas funções específicas. A função específica da linguagem já foi caracterizada de várias maneiras, seja em termos de suas atividades, como em Franchi (1992:25) e, mais recentemente, como em Frank $(2007: 241)^{2}$, seja em termos de sua "serventia", como em Benveniste (1989:220242). Independentemente disso, podemos perguntar o seguinte: como é que conhecia.

${ }^{2}$ Agradeço a Milton do Nascimento por ter chamado minha atenção para esse texto, que eu não 
a linguagem se manifesta, ou emerge? Sua manifestação pode se dar de várias maneiras, mas a mais comum (talvez por ser a mais conveniente) é a linguagem verbal. E, enquanto linguagem verbal, ela assume as características de um sistema adaptativo complexo, de natureza não linear, aberto e, portanto, dissipativo.

Note-se que as características da linguagem enquanto SAC estão presentes também no organismo maior que a aloja, o ser humano (cf. CAMAZINE et al. 2001, JACOB 1983:90-95 e CAPRA 2007:3-25).

Isso posto, passo a considerar, na próxima seção, as características dos sistemas, em geral, e dos sistemas complexos, em particular, para lidar com o tema desse texto, que podemos nomear, tentativamente, como sendo a resolução dos desequilíbrios que ocorrem nas línguas naturais ou, simplesmente, a resolução da variação linguística ${ }^{3}$.

\section{SISTEMAS ADAPTATIVOS COMPLEXOS}

Se entendermos por sistema um conjunto de elementos que se juntam por algum tipo de interação, estabelecendo relações de causa e efeito entre si e formando um todo que se distingue de outros por algum tipo de fronteira, podemos separá-los, de início, entre sistemas de dois tipos: os que se sustentam por forças internas a eles e não estão sujeitos à influência de forças externas, e aqueles cujo comportamento não pode ser previsto apenas em termos de suas forças internas e que têm seu desempenho controlado também pela interação constante que mantêm com seu ambiente. No primeiro caso estamos falando dos sistemas fechados; já no segundo caso estamos falando de sistemas abertos. No caso dos sistemas abertos, portanto, três componentes devem ser levados em conta: o sistema, seu ambiente e a interação entre eles. A linguagem, pelo que conhecemos até aqui, pode ser caracterizada, então, como um sistema aberto, que incorpora múltiplos agentes, os falantes. Além disso, ela pode ser caracterizada, também, como um sistema dinâmico ${ }^{4}$. Sistemas dinâmicos são aqueles que apresentam alterações em seu estado ao longo do tempo. Neste sentido, as línguas naturais fornecem bons exemplos de sistemas dinâmicos, uma vez que elas se encontram em alteração constante, o que se pode observar na variação linguística. Em Oliveira (2014) procurei mostrar que as línguas naturais são um tipo específico de sistema dinâmico, que podemos chamar de sistema adaptativo complexo não linear. Uma característica dos sistemas adaptativos (ou seja, que mudam, quando perturbados, para manter algum tipo de estado invariante, garantindo assim sua sobrevivência) complexos não lineares, que convém retomar aqui, é a de que eles

\footnotetext{
${ }^{3}$ Convém observar que, embora eu esteja dizendo que qualquer abordagem da linguagem deva ser feita em $1^{\text {a }}$ Pessoa, nos termos de Marchetti (2010), vou dirigir meus comentários, nas próximas seções, ao sistema que configura esse órgão. Isso terá a vantagem de simular um tratamento do assunto em $3^{\text {a }}$ Pessoa, em moldes mais familiares. Mas isso não significa que eu abone o tratamento da linguagem, em qualquer de seus aspectos, em $3^{\text {a }}$ Pessoa.

${ }^{4}$ Uma excelente referência sobre sistemas dinâmicos pode ser consultada em Monteiro (2006).
} 
OLIVEIRA - A auto-organização como mecanismo para a resolução da variação linguística têm "memória", no seguinte sentido: num sistema sem memória (ou instantâneo), uma resposta (ou output), num determinado instante, depende apenas do estímulo (ou input) imediato, enquanto num sistema com memória, o output que se obtém num determinado instante depende dos inputs passados. Assim, podemos dizer que o comportamento dos falantes leva em conta não apenas as interações atuais, mas também aquelas que se deram no passado, que são, então, projetadas em seu comportamento futuro.

Sistemas abertos exibem, também, um caráter dissipativo, i.e., eles estão abertos à troca de energia e/ou matéria. Em outras palavras, sistemas dissipativos podem ser influenciados por forças externas a ele como, por exemplo, o meio ambiente. Assim, pode-se dizer que o comportamento dos falantes se molda sob a influência de vários fatores, aí incluído o seu entorno social. Em termos da Teoria da Catástrofe, sistemas dissipativos são aqueles que exibem mudanças qualitativas repentinas em seu comportamento como consequência de alterações pequenas nas circunstâncias que o cercam. Em Oliveira (2015), numa perspectiva de linguagem em primeira pessoa, i.e., sem a exclusão do organismo que a comporta (o falante), procurei mostrar como a variabilidade condicionada por atratores do tipo ciclo limite é reorganizada em termos de atratores não periódicos, ecológica e etologicamente. Isso sugere, então, algum tipo de precedência do efeito de atratores não periódicos sobre atratores periódicos.

Resumindo, nos textos de 2014 e 2015 procurei mostrar que a variação linguística é a situação esperada, se considerarmos a linguagem como um sistema adaptativo complexo.

Se, contudo, a heterogeneidade é estimulada pela própria natureza da linguagem, como é que o caos não se instaura? Ele não se instaura exatamente por conta da auto-organização, condicionada pela natureza dissipativa dos sistemas adaptativos complexos. Em outras palavras, para que a auto-organização seja possível, é necessário levar em conta a natureza do contexto em que a linguagem acontece. O que estou propondo aqui, a ser demonstrado ainda, é que os atratores não periódicos exercem pressão na remodelagem dos atratores periódicos (e, eventualmente, na reconfiguração do espaço de fases), ou seja, na minimização da variação.

\section{AUTO-ORGANIZAÇÃO}

Sistemas complexos apresentamfeedback (daqui em diante, retroalimentação), que pode ser de dois tipos, negativo e positivo. A retroalimentação consiste na utilização do output (ou parte do output) de um sistema para realimentar seu próprio input. Ou seja, uma vez retroalimentado, o sistema processa um novo input, i.e., um input que já não é mais o mesmo. Em outras palavras, sua dinâmica é alterada de algum modo. Caso essa nova dinâmica aumente o desvio (ou erro) do resultado esperado para o estado inicial do sistema, ampliando seu desequilíbrio e desestabilizando seus efeitos, temos uma retroalimentação positiva. A retroalimentação positiva, ou autocatálise, acontece quando um 
Cadernos de ESTUDOS LINGUÍSTICOS (58.3) - set./dez. 2016

determinado evento aumenta as chances de ocorrência de um evento similar. Caso um comportamento emergente surja da interação entre os falantes, e caso ele seja amplificado, espalhando-se para um número cada vez maior de falantes, temos aí a retroalimentação positiva. Se isso resultar num comportamento coletivo regular, estamos diante de um caso de auto-organização. A partir daí a retroalimentação tende a reduzir o desvio do novo estado inicial, produzindo maior estabilidade, naquilo que chamamos de retroalimentação negativa. A retroalimentação negativa acontece quando a ocorrência de um determinado evento torna menos provável a ocorrência de eventos semelhantes.

A retroalimentação pode se dar pela interação entre os elementos internos de um sistema, ou entre os elementos internos do sistema e o seu ambiente. É nessa alternância entre retroalimentação positiva e retroalimentação negativa que acontece a auto-organização. Mas o que é auto-organização? Segundo Camazine et al. (2001:8), "Self-organization is a process in which pattern at the global level of a system emerges solely from numerous interaction among the lower-level components of the system". Ou seja, trata-se da emergência de ordem numa escala mais alta, fomentada por interações que se dão numa escala mais baixa. Convém notar que esse padrão mais alto é uma propriedade emergente do sistema, e não uma propriedade imposta ao sistema por alguma influência externa. Dito de outro modo, o sistema leva em conta, dissipativamente, o seu entorno, uma vez que esse mesmo sistema não opera no vácuo, mas é ele que promove a auto-organização. A auto-organização envolve, portanto, os elementos internos ao sistema, i.e., seus agentes (os falantes) e as interações entre eles, assim como todo o ambiente em que essas interações se dão. Pode-se dizer, portanto, que a auto-organização promove o melhor ajuste possível entre um sistema e seu ambiente ${ }^{5}$. A auto-organização se identifica, portanto, como uma emergência (i.e., o surgimento de uma estrutura hierarquicamente mais alta), gerenciada pela retroalimentação.

\section{ATRATORES}

Consideremos agora a questão dos atratores. Um atrator, num sistema dinâmico, pode ser considerado como um formador de padrão. Assim sendo, um atrator pode se identificar com elementos (ou parâmetros) que configuram um determinado estado de um sistema, ou um conjunto de estados, para o qual/ os quais estados vizinhos tendem a convergir. Em suma, os atratores moldam o espaço de fases (ou espaço base). Cada ponto deste estado de fases determina um estado do sistema. Se esse estado é único, temos um atrator de ponto fixo (que vai nos interessar mais adiante). Se, contudo, esse estado não é único, mas ainda assim delimitado pelos parâmetros que caracterizam esse espaço de fases, então temos um atrator ciclo-limite, que permite vários estados (ou vários pontos nesse espaço de fases). Um exemplo disso, já comentado em Oliveira (2014; 2015), pode ser

\footnotetext{
${ }^{5}$ Penso que a noção de affordance de Gibson (1986) cabe perfeitamente aqui.
} 
dado pelas vogais médias pretônicas do português brasileiro, /e/ e /o/, cujos estados (ou formas fonéticas) são regulados apenas em termos dos parâmetros [- baixo] e [ $\alpha$ posterior]. Atratores do tipo ciclo-limite são periódicos. No caso em questão, qualquer estado do sistema das médias pretônicas deverá oscilar entre alguma das possíveis combinações permitidas pelos parâmetros acima. Isso se dá de modo previsível, na medida em que nenhuma outra realização fonética poderá ocorrer fora desses parâmetros. Assim sendo, as únicas realizações fonéticas possíveis serão $[\varepsilon, \mathrm{e}, \mathrm{i}]$ e $[0, \mathrm{o}, \mathrm{u}]$. O que não se pode prever aqui, no entanto, é como essas mesmas formas fonéticas permitidas como estados possíveis desse espaço de fases irão ocorrer em relação a elementos que estão fora desse espaço, como as palavras, os falantes e a área dialetal. O que se observa nesses casos é uma espécie de movimento caótico, irregular que, embora possa ser associado a uma causa $x$, são imprevisíveis. Esse tipo de atrator é, portanto, não periódico e é chamado de atrator estranho.

\section{AUTO-ORGANIZAÇÃO E ATRATORES PERIÓDICOS}

Nesta seção comento alguns casos razoavelmente conhecidos que mostram como a auto-organização reequilibra um sistema que foi temporariamente perturbado ${ }^{6}$. Podemos começar pelos casos mais simples, aqueles em que um "desequilíbrio" temporário é resolvido pela eliminação de uma das possibilidades. A literatura em linguística histórica está repleta de casos como esses. Vou utilizar aqui um caso frequentemente mencionado nos estudos variacionistas, inicialmente relatado por Gauchat em seu estudo de Charmey, em 1905. Esse caso é retomado em Labov (1972:275-278). Gauchat observou em Charmey uma alternância entre $[K]$ e $[y]$ que se distribuía por faixa etária da seguinte maneira ${ }^{7}$ :

$\begin{array}{ll}\text { Faixa etária } & \text { Variante } \\ 60-90 \text { anos } & {[\Lambda]} \\ 30-60 \text { anos } & {[\Lambda] \sim[\mathrm{y}[} \\ <30 \text { anos } & {[\mathrm{y}]}\end{array}$

${ }^{6}$ Teríamos, de início, duas maneiras de testar como as línguas naturais agem enquanto SAC's. A primeira delas seria por algum tipo de modelagem matemática, o que está fora do meu alcance. A segunda seria pela verificação de casos razoavelmente conhecidos, e é por esse viés que vou desenvolver minha argumentação.

${ }^{7} \mathrm{O}$ trabalho de Gauchat não nos permite saber se, em cada uma das faixas etárias, havia, ou não, variação, mesmo que em graus diferentes. A situação descrita dá a impressão de ocorrências categóricas para as variantes em questão nas faixas etárias mais novas e mais velhas. Pessoalmente, tenho minhas dúvidas de que a situação tenha sido mesmo assim. 
Em 1929, 24 anos após a publicação do trabalho de Gauchat, Hermann (apud LABOV 1972:276-278) encontrou, contudo, apenas a realização [y]. Esse é um caso claro daquilo que Labov (2010) chama de "convergência", ou seja, como se trata de uma mesma comunidade, o que se espera é a convergência, e não a manutenção de algum tipo de divergência. $O$ fator que pode estar por detrás dessa convergência é aquilo que Bloomfield (1933:476) afirma: "Every speaker is constantly adapting his speech-habits to those of his interlocutors". Casos como este podem ser encontrados na história de qualquer língua, e exibem o modo mais drástico de se lidar com um desequilíbrio momentâneo. Resumindo, um sistema controlado por um atrator de ponto fixo, que tinha apenas $[K]$ como output, se desequilibra momentaneamente, configurando-se como bimodal, com duas saídas possíveis, $[K] \sim[\mathrm{y}]$, mostrando variação em contextos idênticos. A "solução" para esse desequilíbrio, conduzindo a um novo estado de equilíbrio, consiste no retorno a um estado monomodal, com um atrator de ponto fixo em favor da forma inovadora. $\mathrm{O}$ que podemos ver neste caso é a atuação de uma retroalimentação positiva, que amplia a ocorrência da forma inovadora [y], na geração intermediária, estabilizada por uma retroalimentação negativa, que diminui paulatinamente a ocorrência de $[\kappa]^{8}$.

Outro exemplo de natureza semelhante, mas que ainda não atingiu um estado de equilíbrio total pode ser dado pelo estudo de Blondeau, Sankoff \& Charity (2003). O que este trabalho nos mostra é que a alternância, no francês de Montreal, entre uma vibrante alveolar [ $\mathrm{r}$ ] e uma vibrante uvular [R] caminha para um desfecho em favor desta última. Em termos dos percentuais encontrados para a variante [R], temos o seguinte: em 1971, 37\%; em 1984, 49\% e em 1995, 62\%. Como se trata, à semelhança do caso de Gauchat, de variação em contextos idênticos, o que se espera, ao longo do tempo, é algo semelhante ao que ocorreu em Charmey, a menos que algum fator novo (a atuação de um atrator não periódico, por exemplo) promova a reversão dessa situação.

Vejamos agora alguns outros casos que ainda são simples, mas nem tanto. Como primeiro exemplo vou retomar aqui outro trabalho clássico dos estudos variacionistas, relativo à pesquisa de Labov em Martha's Vineyard, em 1963 (reimpresso em LABOV 1972:1-42). O caso tratado é o da centralização (ou alçamento) do núcleo dos ditongos (ay) e (aw) na ilha de Martha's Vineyard. O objetivo principal desse texto de Labov é o de mostrar que há uma motivação social para uma mudança sonora específica, a centralização do núcleo dos dois ditongos. O texto contempla várias facetas da questão, mas vou me ater aqui àquilo que se observa com relação à centralização do núcleo do ditongo (aw) ao longo do tempo. O que Labov observa em seu estudo, para esse caso específico, é que os informantes mais velhos, na faixa etária acima de 85 anos, mostram um índice baixo de centralização do núcleo. Ou seja, esses informantes apresentam em sua fala uma maioria esmagadora de núcleos não alçados ou minimamente alçados, em comparação com a presença de algum tipo mais acentuado de alçamento. Por outro lado, informantes na faixa etária entre os 60 e os 85 anos

\footnotetext{
${ }^{8}$ Num caso claro de refonologização, na terminologia de Jakobson (1931).
} 
passam a apresentar uma distribuição bem equilibrada entre formas alçadas e não alçadas. Contudo, os informantes de 60 anos para baixo apresentam uma distribuição diferente para os núcleos alçados e não alçados: as formas extremas de alçamento passam a se alinhar na presença de uma obstruinte surda seguinte enquanto as formas menos alçadas se distribuem na presença de algum outro tipo de segmento! Esse é um caso clássico de bifurcação controlada por parâmetros internos ao sistema ${ }^{9}$. Bifurcações são pontos em que algo se divide em dois ramos, numa mudança qualitativa no tipo de atrator, que resulta da alteração de algum parâmetro (cf. ARNOLD 1989). Note-se que, nesses casos, o sistema também apresenta uma natureza bimodal, uma vez que ele assume dois pontos de convergência, ou dois estados, com alçamento máximo diante de obstruintes surdas e sem alçamento, ou com alçamento mínimo, nos demais ambientes. Ou seja, aquilo que os informantes entre 60 e 85 anos apresentavam como desequilíbrio foi resolvido pelos informantes mais jovens em termos de atratores do tipo ciclo-limite. Resumidamente, podemos dizer o seguinte: uma variação "livre" que, a princípio, desequilibra o sistema, pode se autorreorganizar como variação "condicionada", retomando o equilíbrio do sistema, desde que algum parâmetro novo venha a fazer parte de um novo espaço de fases. Nesse caso, as obstruintes surdas, um parâmetro não contemplado inicialmente, funcionam como atratores ciclo-limite na auto-organização do sistema, que havia sido temporariamente desequilibrado por uma espécie de "variação livre" na faixa etária entre 60 e 85 anos.

Outro exemplo semelhante a este pode ser dado pela palatalização de /t/ e /d/ no português brasileiro falado na região sudeste. No dialeto de Belo Horizonte, por exemplo, temos [t] e [d] diante de [i] (que pode vir de /i/ ou /e/ subjacentes), enquanto [t] e [d] ocorrem nos demais ambientes. Mas é legítimo pensar que em algum ponto do tempo ocorreu a variação entre [t] e [t], por um lado, e entre [d\}] e [d], por outro lado, diante de [i]. Essa variação foi "resolvida" numa distribuição em termos de alofonia condicionada. Aliás, algo parecido pode estar ocorrendo no sul do Brasil, ainda de forma incipiente. É o que podemos ver em Battisti (2010), para a comunidade de Antônio Prado (RS). Segundo Battisti, essa palatalização ainda é modesta, por volta de 30\% dos casos. Referindo-se a um trabalho anterior, de Battisti, Dornelles Filho, Lucas \& Bovo (2007), Battisti (2010:276) nos apresenta a seguinte situação para a palatalização de /t/ e /d/ em Antônio Prado:

Diante de

/i/ fonológico

[i] fonético

\section{Percentual de Palatalização}

$59 \%$

$13 \%$

${ }^{9}$ Pope (2002), num estudo que replica fielmente a metodologia de Labov (1963) na mesma comunidade, observou que, 40 anos depois, o alçamento de (aw) havia aumentado bastante, muito embora o alçamento de (ay) mostrasse uma tendência à diminuição. 
Cadernos de ESTUDOS LINGUUíSTICOS (58.3) - set./dez. 2016

Como se pode ver, um desequilíbrio, oriundo da divergência (foneticamente controlada), está sendo criado e deverá ser resolvido por algum tipo de autoorganização.

Com base nos casos comentados até aqui proponho a seguinte hipótese:

Hipótese 1: Um estado de desequilíbrio em um sistema linguístico, provocado pela variação livre, será auto-(re)organizado pela (a) eliminação de uma das variantes, permanecendo monomodal, ou (b) pela distribuição dessas mesmas variantes em ambientes mutuamente excludentes, passando a bimodal. Em ambos os casos, o espaço de fases é alterado.

Observe-se que a Hipótese 1 leva em consideração algum tipo de autoorganização controlada apenas por atratores periódicos, do tipo ciclo-limite. Mas, conforme já dissemos, nenhum sistema atua no vácuo, estando, portanto, sujeito às influências do contexto em que ocorre. Essa é a natureza dos sistemas abertos, dissipativos. E, nesses casos, as coisas deixam de ser "simples" e começam a contrariar as propostas ingênuas feitas para a análise da variação numa perspectiva em $3^{\mathrm{a}}$ Pessoa.

\section{AUTO-ORGANIZAÇÃO E ATRATORES NÃO PERIÓDICOS}

Passemos então aos casos em que se faz presente a atuação de algum tipo de atrator não periódico. Esses casos são interessantes e retomam a questão maior de Labov (2010), envolvendo convergência e divergência. Segundo Labov, a divergência é esperada quando duas comunidades de fala estão separadas, de forma que a comunicação entre elas se torna reduzida. Assim, falantes de áreas dialetais diferentes podem se ver envolvidos, na interação face a face, em incompreensões mútuas (cf. LABOV 2010:48-58). O que não se espera, contudo, é a presença da divergência quando duas comunidades de fala estão em comunicação contínua, fato que vai exigir algum tipo de explicação (cf. LABOV 2010:5). No capítulo 7 de seu livro (2010:155-164) Labov nos fala de "forks in the road", referindo-se ao desenvolvimento divergente que pode afetar dois dialetos vizinhos. Sua ideia básica é a seguinte: algum evento-gatilho levou à situação em que dois dialetos vizinhos acabaram apresentando um desenvolvimento divergente. Convém observar que toda a discussão de Labov envolve o complicado sistema de vogais do inglês americano, o que não nos interessa diretamente, aqui. Contudo, é muito interessante aquilo que Labov chama de "forks in the road". Os casos que ele apresenta não são casos em que um mesmo espaço de fases se reorganiza, mas são casos em que temos o surgimento de dois espaços de fases diferentes. Para representar isso Labov se vale de um modelo em dois estágios (v. p. 156), que podemos replicar aqui: 
OLIVEIRA - A auto-organização como mecanismo para a resolução da variação linguística

Condição de instabilidade
Forks in the road
Mudança bidirecional
Mudança unidirecional

(Adaptado de LABOV 2010:156)

O que importa nesse esquema é o seguinte: na mudança bidirecional, o que pode levar a uma opção por A ou B? Feita a opção por A ou B, como é que ambos passam a A' e B', respectivamente? ${ }^{10}$

Para exemplificar esses casos de auto-organização, vou retomar algumas análises já propostas para o português brasileiro. Conforme vimos na seção anterior, a palatalização de /t, d/ é um processo em estado incipiente em algumas regiões do Brasil (cf. BATTISTI 2010; BATTISTI et al. 2007). Em outras regiões, contudo, a alternância entre oclusivas e africadas já se estabilizou, numa alofonia condicionada. Se considerarmos a distribuição espacial desse processo, veremos que a palatalização se estabilizou nas áreas geográficas centrais dos falares brasileiros, como no Rio de Janeiro (cf. ABAURRE \& PAGOTTO 2013; CALLOU 2015; MOTA \& CARDOSO 2015), e também na Região Metropolitana de Belo Horizonte. E, como numa espécie de onda, o processo atinge áreas dialetais adjacentes, numa proporção que vai diminuindo à medida que a distância dessa área central vai aumentando (cf. ABAURRE \& PAGOTTO 2013:199). Não há, contudo, nenhuma área em que a palatalização de /t, d/ não se faça presente em algum grau. O que Abaurre \& Pagotto mostram para a ocorrência de [t] , nas cidades incluídas no projeto NURC, é o seguinte: RJ: 100\%; Salvador: 85\%; São Paulo: 73\%; Porto Alegre: 40\% e Recife: 7\%. Já Callou (2015:60), com base nos resultados obtidos por Quandt (2004), fornece mais alguns percentuais para a palatalização em outras localidades, tais como: Minas Gerais: 98\% para /t/ e /d/; Paraná: 94\% para /t/ e 57\% para /d/; Sergipe: $4 \%$ para $/ \mathrm{t} /$ e $2 \%$ para /d/; Paraíba: $0 \%$ para /t/ e /d/. O processo que gera esse caso de variação, nas áreas onde a alternância ainda não se estabilizou, é, em si, trivial. O que não é trivial é exatamente a sua manifestação quantitativamente diferenciada por áreas diferentes. Se se trata de um processo foneticamente motivado, natural, por que não temos o mesmo comportamento em todas as regiões dialetais, e sim diferenças que vão de $0 \%$ a $100 \%$ ? E de que modo casos como este podem ser tratados numa perspectiva da linguagem enquanto um SAC? O que ocorre neste caso é a atuação de um atrator não periódico (strange attractor) que tem a ver com a interação entre o sistema, aí incluídos seus agentes (os falantes) e as interações entre esses agentes, e seu ambiente, aí incluídos outros fatores como as regiões geográficas e os parâmetros e valores sociais relativos a cada uma delas. Em casos como esse, o que se observa são variações nos parâmetros de controle, sejam eles geográficos e/

${ }^{10}$ Ao considerar as mudanças unidirecionais Labov se vale, basicamente, dos princípios de mudança vocálica em cadeia, propostos em Labov, Yaeger \& Steiner (1972) e refinados no cap. 6 (2010: 120-154). 
Cadernos de ESTUDOS LINGUÍSTICOS (58.3) - set./dez. 2016

ou sociais, o que leva a uma mudança qualitativa na dinâmica do sistema, beirando o caos. De fato, quando observado em sua totalidade, a palatalização variável de /t, d/ no português brasileiro apresenta um comportamento que sugere uma situação caótica. Isso porque, nesse caso, os estados possíveis do sistema não convergem nem para um ponto fixo (i.e., não há relatos de situações onde só aparecem as formas $[\mathrm{t}] \mathrm{e}[\mathrm{d}]^{11}$ ) e nem apresentam a mesma periodicidade para [t] e [d\}], o que se reflete nas proporções diferenciadas para sua ocorrência por região. O que se observa são trajetórias sem periodicidade (ou atratores não periódicos). Se nos valermos da terminologia de Labov (2010), podemos dizer que estamos diante de um "fork in the road" que conduz a "mudanças bidirecionais" (ou bifurcações). Na variedade do Rio de Janeiro (cf. ABAURRE \& PAGOTTO 2013:199), assim como em Belo Horizonte, o sistema já se estabilizou, de maneira bimodal, numa alofonia condicionada. Para as outras regiões, e com base nos números apresentados acima e na convicção de que os sistemas tendem, infalivelmente, a se autorreorganizarem, podemos "prever" uma solução semelhante para Salvador e São Paulo. Quanto a Recife (e, talvez, Pernambuco), assim como para Sergipe e Paraíba, a expectativa é a de uma estabilização num ponto fixo, como oclusivas, no sentido contrário ao de Salvador e São Paulo (cf. também MOTA \& CARDOSO 2015:76). Essa expectativa é fortemente justificada pelas frequências apresentadas para Recife em Abaurre \& Pagotto (2013:203), com relação à distribuição da variante [t] ] por faixa etária. O que se observa no geral, para o caso de Recife, é um índice baixo de ocorrência de [t]], independentemente da faixa etária. Mas, além disso, os mais jovens $\left(1^{\mathrm{a}}\right.$ e $2^{\mathrm{a}}$ faixas etárias) apresentam índices de palatalização de /t/ (6\% e 5\%, respectivamente) que reduzem pela metade o índice apresentado pelos informantes mais velhos, da $3^{\mathrm{a}}$ faixa etária (11\%)! Já no caso de Porto Alegre, não seria prudente arriscar nenhuma previsão mais ousada, exatamente pela semelhança de comportamento que se observa para as faixas etárias mais altas e mais baixas ${ }^{12}$.

Resumindo, considerando-se o espaço como atrator não periódico, podemos entender o quadro divergente nas variedades do português brasileiro no que se refere à palatalização de /t, d/. Esse parâmetro de controle (o espaço) é um "fork in the road"13. Em cada caso desses há uma retroalimentação positiva, que amplia uma das ocorrências, atuando em conjunto com uma retroalimentação negativa, que inibe a ocorrência alternativa. Eventualmente se chega a um novo estado de estabilidade no sistema, como já aconteceu nas variedades do Rio de Janeiro e Belo Horizonte, numa distribuição bimodal ou, alternativamente, como parece estar acontecendo em Recife, Sergipe e Paraíba, em favor de um atrator de ponto fixo. Ou seja, nas mudanças unidirecionais a auto-organização vai acontecer e, é claro, outras perturbações virão. É isso que caracteriza um sistema dinâmico.

${ }^{11}$ Exceto pelo relato de Callou/Quandt para a Paraíba, mas nesse caso a questão nem se coloca, uma vez que o sistema nunca se desequilibrou.

${ }^{12}$ É claro que não se trata apenas disso. Há também um desconhecimento de minha parte de outros tipos de regulação social da palatalização em Porto Alegre.

${ }^{13}$ De Boer (2005:129) escreve o seguinte: “Also, spatial structure can be given to the population: agents have a spatial location, and agents that are closer together have a higher probability of interacting than agents further apart". Trata-se, evidentemente, de uma retomada daquilo que Bloomfield já dizia em 1933. 
Um segundo caso que podemos considerar aqui tem a ver com as vogais médias pretônicas. Esse é outro caso clássico da dialetologia do português brasileiro, que tem recebido muita atenção. Em Oliveira (2015) sugeri, com base neste mesmo caso das vogais médias pretônicas, que a propagação dos processos responsáveis por suas realizações fonéticas diferenciadas deveria ser tratada ecologicamente, i.e., levando-se em conta a interação entre um organismo e seu nicho sociocultural. Entendendo-se por organismos os agentes de um sistema linguístico, em interação com outros agentes e em affordance com seu nicho sociocultural, a proposta feita ali era, na verdade, muito simples: "Cada falante, portanto, em busca da affordance ótima, irá refletir os traços de seu ambiente, de seu nicho, num padrão fractal" (p.66). Se isto é verdade, então podemos esperar distribuições diferentes para as realizações fonéticas possíveis das vogais médias pretônicas por região. E é exatamente isso o que acontece, a julgar pelos percentuais apresentados por Brandão (2015:13, 18-19) e Mota \& Cardoso (2015: 68-69). Basicamente, o que encontramos aí é o seguinte:

A - Em cidades do nordeste, como Salvador e Recife, os percentuais de ocorrência de vogais médias abertas, em posição pretônica, são de $60 \%$ e $47 \%$, respectivamente.

B - Em cidades do sul e sudeste, como Porto Alegre e São Paulo, o percentual de ocorrência de vogais médias abertas, nesta mesma posição, é de $0 \%$.

Ora, isso mostra duas coisas: primeiro, a atuação de um atrator não periódico (região) agindo de modo claro numa bifurcação e, segundo, em ambos os casos esse mesmo atrator aponta para uma direção possível da resolução da instabilidade que existe, uma vez que as variantes abertas, $[\varepsilon]$ e [o] concorrem com variantes fechadas ([e] e [o]) e com variantes alçadas ([i] e [u]). A situação para Recife e Salvador (e, muito provavelmente, para a maioria das cidades nordestinas) pode ser representada por uma tendência monomodal em $[\varepsilon] /[0]$, com resíduos em $[\mathrm{e}] /[\mathrm{o}]$ e $[\mathrm{i}] /[\mathrm{u}]$. Já para São Paulo e Porto Alegre a tendência seria também monomodal, mas com a moda em [e]/ [o] e resíduos em $[\varepsilon] /[o]$ e $[i] /[u]$. Segundo Carmo (2013:174) o percentual de vogais médias pretônicas na forma média fechada, no noroeste paulista, é de $83,7 \%$, ocorrendo apenas $16,3 \%$ de alçamentos (e $0 \%$ de ocorrências na forma média aberta). Um caso interessante de análise deste mesmo fenômeno pode ser visto em Dias (2014) que, examinando os fatos relativos a três localidades de Minas Gerais, Ouro Branco, Piranga e Machacalis, nos mostra, de modo convincente, que em Machacalis a tendência para uma possível reorganização do sistema vai na mesma direção das cidades nordestinas, ou seja, com a moda em $[\varepsilon] /[\circ]$, enquanto em Ouro Branco e Piranga a moda vai na direção de [e]/ [o]. E se as coisas são assim, então podemos supor que os dialetos regionais tenderão a ficar cada vez mais diferenciados entre si, uma vez que a escolha da moda preferencial é diferenciada (ou, pelo menos, não há a menor garantia de que ela será a mesma). 
Cadernos de ESTUDOS LINGUÍSTICOS (58.3) - set./dez. 2016

Além do atrator não periódico região, outros atratores da mesma natureza acabam interferindo e provocando bifurcações menores, quase individuais. É o caso do léxico, seja ele visto globalmente, ou na relação entre itens léxicos específicos e os falantes individuais. Uma coisa que podemos dizer, de início, é que a relação estabelecida entre agentes individuais e o léxico, em termos de sua composição sonora, deve ser encaixada numa estrutura hierarquicamente mais alta, aquela estabelecida pelo atrator região. Isso quer dizer que os ajustes, ainda que individuais, são mais semelhantes entre si dentro de uma mesma área geográfica. Fato é que o léxico tem mostrado um efeito perturbador nas propostas mais frequentes para se acomodar algum efeito estrutural seguro na análise da variação ou da mudança. Para exemplificar esse caso, vou recorrer a outro texto clássico, Bloomfield (1933:321345). O que acontece com Bloomfield é que ele se vê numa situação incômoda em seu capítulo 19, sobre geografia linguística. Aí se pode ver que as grandes isoglossas são simplesmente desrespeitadas pelo léxico. E são vários os exemplos disso. Um desses casos diz respeito à grande isoglossa que separa os dialetos alemães do norte dos dialetos do sul. Essa isoglossa, chamada de linha maken-maxen, supostamente separaria ao norte as palavras faladas com uma obstruinte oclusiva, daquelas que ao sul são faladas com obstruinte fricativa. Então, era de se esperar que ao norte, onde ocorre maken, ocorressem também ik, dat e $\operatorname{dorp}^{14}$. E, de fato, ao norte dessa isoglossa encontramos $i k$, mas encontramos também $i x$. Para complicar ainda mais as coisas, ao lado de das e dorf, abaixo da isoglossa, encontramos também dat e dorp! E não é esse o único exemplo de mau comportamento por parte do léxico; há ainda outros casos que envolvem dialetos holandeses. Bloomfield, um neogramático convicto e também um linguista honesto, acaba se rendendo aos fatos e escreve o seguinte:

"All this shows that the spread of linguistic features depends upon social conditions. The
factors in this respect are doubtless the density of communication and the relative prestige
of different social groups. Important social boundaries will in time attract isogloss-lines.
Yet it is evident that the peculiarities of the several linguistic forms themselves play a part,
since each is likely to show an isogloss of its own". (345)

Como se pode ver, Bloomfield antecipa muito daquilo que se diz atualmente sobre SAC's, como o leitor poderá verificar por si mesmo.

Em Belo Horizonte que conheço de perto, encontramos algo semelhante, envolvendo a realização fonética das vogais médias pretônicas. A realização fonética para essas vogais, em Belo Horizonte, sugere uma distribuição bimodal, numa disposição intermediária entre o padrão monomodal geral do nordeste e aquele que se observa, grosso modo, no padrão geral também monomodal que cobre a área que vai de São Paulo até o extremo sul. Em Belo Horizonte concorrem, em pé de igualdade, $[\mathrm{e}] /[\mathrm{i}]$, para a série anterior, e $[\mathrm{o}] /[\mathrm{u}]$, para a série posterior ${ }^{15}$.

${ }^{14}$ É claro que não estou usando aqui a representação ortográfica oficial para essas palavras em alemão. Estou apenas mantendo a representação utilizada no texto de Bloomfield.

${ }^{15} \mathrm{O}$ caso da ocorrência das formas abertas em posição pretônica, [ $\left.\varepsilon\right]$ e [0], está sujeito a uma série de controles mais finos (qualidade da vogal tônica seguinte, padrão silábico) que vão exigir um tratamento diferenciado. De qualquer forma, essas ocorrências constituem uma minoria. 
OLIVEIRA - A auto-organização como mecanismo para a resolução da variação linguística

Contudo, quando observamos a distribuição dessas alternâncias pelo léxico, assim como na relação \{léxico-indivíduo\}, o caos aparente começa a mostrar um padrão que aponta para a mudança de classe fonológica de inúmeras palavras, afetando diretamente a representação subjacente das mesmas ${ }^{16}$.

É evidente que aquilo que comentei nessa seção diz respeito, apenas, aos casos de bifurcação (ou mudanças bidirecionais). O ajuste fino, na autoorganização, deverá levar em conta uma reconfiguração do espaço de fases (ou seja, será unidirecional). Ainda assim, penso que seja possível avançar aqui uma segunda hipótese, que enuncio numa versão forte:

Hipótese 2: Perturbações nos sistemas são sempre promovidas por atratores não periódicos.

Essa afirmação diz, simplesmente, que a variação linguística só ocorre no contexto social e em função dele, exatamente como Meillet (1906, apud WEINREICH, LABOV \& HERZOG 1968:176) sugere e como Labov (1972:178180) afirma e prova (2001:498-511). Eu diria ainda que a atuação dos atratores não periódicos pode apontar também para uma direção específica a ser tomada na auto-organização do sistema. Essa auto-organização, por sua vez, será confirmada no desenho de um novo espaço de fases, controlado por atratores periódicos, conforme sugeri na Hipótese 1, apresentada ao final da seção 6.

\section{CONCLUSÃo}

Minha conclusão é bem simples e direta. Os casos que comentei aqui, no intuito de mostrar como a variação se resolve ou, dito de outra forma, como sistemas se refazem de algum estado de perturbação (ou se auto-organizam), me permitem algumas conclusões:

1 - Se as hipóteses 1 e 2 se mostrarem corretas, então não temos como escapar de uma abordagem de natureza etológica e ecológica da variação linguística, uma vez que isso faz parte da natureza dos sistemas adaptativos complexos;

2 - Parece-me evidente, a partir dos casos comentados, que os atratores não periódicos têm precedência sobre os atratores periódicos na dinâmica de desequilíbrio e reequilíbrio dos sistemas linguísticos. Isso sugere também que a linguagem se presta, primordialmente, à manutenção dos organismos (leia-se, dos falantes) em seu nicho. Conforme dizia Benveniste, ela serve para se viver.

\footnotetext{
${ }^{16}$ Essa sugestão certamente causaria uma reação contrária por parte de um fonólogo de índole gerativista. 
3 - Se as conclusões 1 e 2 acima estiverem corretas, então podemos concluir também que Meillet e Labov estavam certos o tempo todo ${ }^{17}$.

\section{REFERÊNCIAS BIBLIOGRÁFICAS}

ABAURRE, Maria Bernadete M.; PAGOTTO, Emilio Gozze. Consoantes em ataque silábico: palatalização de /t, d/. In: ABAURRE, Maria Bernadete M. A construção fonológica da palavra. São Paulo: Editora Contexto, 2013, p. 195-236.

ARNOLD, Vladimir I. Teoria da catástrofe. Campinas: Editora da Unicamp, 1989.

BATTISTI, Elisa; DORNELLES FILHO, Adalberto A.; LUCAS, João I. P.; BOVO, Nínive M. P. Palatalização das oclusivas alveolares e a rede social dos informantes. Revista virtual de estudos da linguagem - ReVEL vol. 5, n. 9, p. 1-29, agosto, 2007.

BATTISTI, Elisa. Variação. In: BISOL, Leda; SCHWINDT, Luiz Carlos (orgs.). Teoria da Otimidade: Fonologia. Campinas: Pontes Editores, 2010, p. 271-290.

BENVENISTE, Émile. Problemas de Linguística Geral II. Campinas: Pontes Editores, 1989.

BLONDEAU, Hélène; SANKOFF, Gillian; CHARITY, Anne. Parcours individuels et changements linguistiques en cours dans la communauté francophone montréalaise. Revue Québécoise de Linguistique 31, p. 13-38, 2003.

BLOOMFIELD, Leonard. Language. New York: Holt, 1933.

De BOER, Bart. Self-organisation in language. In: HEMELRIJK, C. (ed.) Proceedings of the international workshop on Self-organization and Evolution of Social behavior. Cambridge: Cambridge University Press, 2005, p. 123-139.

BRANDÃO, Silvia Figueiredo. Variação e mudança no âmbito do vocalismo. In: MARTINS, Marco Antonio; ABRAÇADO, Jussara (orgs.), Mapeamento sociolinguístico do português brasileiro. São Paulo: Editora Contexto, 2015, p. 11-38.

CALLOU, Dinah. Variação e mudança no âmbito do consonantismo. In: MARTINS, Marco Antonio; ABRAÇADO, Jussara (orgs.), Mapeamento sociolinguístico do português brasileiro. São Paulo: Editora Contexto, 2015, p. 39-64.

CAMAZINE, Scott; DENEUBOURG, Jean-Louis; FRANKS, Nigel R.; SNEYD, James; THERAULAZ, Guy; BONABEAU, Eric. Self-organization in biological systems. Princeton: Princeton University Press, 2001.

CAPRA, Fritjof. Complexity and life. In: CAPRA, Fritjof; JUARRERO, Alicia; SOTOLONGO, Pedro; van UDEN, Jacco. (eds.), Reframing complexity - Perspectives from the North and South. Mansfield: ISCE Publishing, 2007, p. 3-25.

CARMO, Maria Cristina do. As vogais médias pretônicas na variedade do interior paulista. Tese (Doutorado em Linguística) - IBILCE, UNESP, São José do Rio Preto, 2013, 294 páginas.

\footnotetext{
${ }^{17}$ Mas não, necessariamente, pelas mesmas razões que eu teria para apontar para essa correção. As minhas eu procurei evidenciar no texto, checando-as com os resultados que eu esperava, na perspectiva que adotei, mesmo que eles tivessem vindos de análises feitas em outro diapasão.
} 
OLIVEIRA - A auto-organização como mecanismo para a resolução da variação linguística

DIAS, Melina Rezende. Estudo comparativo da variação das vogais médias pretônicas em falares mineiros. Tese (Doutorado em Linguística), Universidade Federal de Minas Gerais, Belo Horizonte, 2014, 372 páginas.

FRANCHI, Carlos. Linguagem - atividade constitutiva. Cadernos de Estudos Linguísticos 22, UNICAMP, p. 9-40, 1992.

FRANK, Roslyn M. The language-organism-species analogy: A complex adaptive systems approach to shifting perspectives on "language". In: FRANK, Roslyn M.; DIRVEN, René; ZIENKE, Tom; BERNÁRDEZ, Enrique. (eds.), Body, Language and Mind - Volume 2: Sociocultural Situatedness. Berlin - New York: Mouton de Gruyter, 2007, p. 215-262.

GIBSON, James J. The ecological approach to visual perception. New York: Psychology Press, 1986.

HAUSER, Marc D.; CHOMSKY, Noam; FITCH, W. Tecumseh. The faculty of language: what is it, who has it, and how did it evolve? In: LARSON, Richard K., DEPREZ, Viviane; YAMAKIDO, Hiroko. (eds.): The evolution of language - Biolinguistic perspectives. Cambridge: Cambridge University Press, 2010, p. 14-42.

JACOB, François. A lógica da vida. Rio de Janeiro: Edições Graal, 1983.

JAKOBSON, Roman. Principles of historical linguistics. In: BALDI, Philip; WERTH, Ronald N. (eds.). Readings in historical phonology - Chapters in the theory of sound change, The Pennsylvania State University Press, 1978/1931, p. 103-120.

LABOV, William. Sociolinguistic Patterns. Philadelphia: University of Pennsylvania Press, 1972.

LABOV, William. Principles of Linguistic Change, Vol. 2 - Social Factors. Oxford: Blackwell, 2001.

LABOV, William. Principles of Linguistic Change, Vol. 3 - Cognitive and Cultural Factors. Oxford: Wiley-Blackwell, 2010.

LABOV, William; YAEGER, Malcah; STEINER, Richard. A quantitative study of sound change in progress. Philadelphia: US Regional Survey, 1972.

MARCHETTI, Giorgio. Consciousness, Attention and Meaning, New York: Nova Science Publishers Inc., 2010.

MOTA, Jacyra Andrade; CARDOSO, Suzana Marcelino. Variação fônica nas capitais brasileiras. In: MARTINS, Marco Antonio; ABRAÇADO, Jussara (orgs.), Mapeamento sociolinguístico do português brasileiro. São Paulo: Editora Contexto, 2015, p. 65-78.

MONTEIRO, Luiz Henrique Alves. Sistemas Dinâmicos. São Paulo: Editora Livraria da Física, 2006.

OLIVEIRA, Marco Antonio. Variação fonológica: o indivíduo e a comunidade de fala. In: CORTINA, Arnaldo; NASSER, Sílvia M. G. C. R. (orgs.), Sujeito e Linguagem, São Paulo: Cultura Acadêmica, 2009, p. 97-115.

OLIVEIRA, Marco Antonio. A variação fonológica na perspectiva da linguagem como um sistema adaptativo complexo. In: MAGALHÃES, José (org.) Linguística in Focus 10: Fonologia. Uberlândia, EDUFU, 2014, p. 11-35.

OLIVEIRA, Marco Antonio. Por uma abordagem etológica e ecológica da variação linguística. In: PARREIRA; Maria Cristina; CAVALARI, Suzi Marques S.; ABREU-TARDELLI, Lília; NADIN, Odair Luiz; COSTA, Daniel Soares (orgs.), Pesquisas em Linguística no século XXI: perspectivas e desafios teóricos-metodológicos. São Paulo: Cultura Acadêmica, 2015, p. 45-70. 
Cadernos de ESTUDOS LINGUÍSTIICOS (58.3) - set./dez. 2016

POPE, Jennifer. The social history of a sound change on the island of Martha's Vineyard, Massachusetts: forty years after Labov. Dissertação de mestrado. Edinburgh: University of Edinburgh, 2002.

QUANDT, Vivian. O comportamento da lateral anterior na fala do norte-noroeste fluminense. Dissertação de mestrado, Universidade Federal do Rio de Janeiro, 2004.

WEINREICH, Uriel; LABOV, William; HERZOG, Marvin I. Empirical foundations for a theory of language change. In: LEHMANN, Winfred Phillip; MALKIEL, Yakov (eds.), Directions for historical linguistics. Austin: University of Texas Press, 1968, p. 85-195. 